\title{
Estimation of maternal serum vitamin D levels and its correlation with gestational diabetes mellitus
}

\author{
Anupriya Narain ${ }^{1 *}$, Alka Goel ${ }^{1}$, Parul Goyal $^{2}$ \\ ${ }^{1}$ Department of Obstetrics and Gynecology, ${ }^{2}$ Department of Biochemistry, PGIMER and Dr RML Hospital, New
} Delhi, India

Received: 11 June 2018

Accepted: 03 July 2018

*Correspondence:

Dr. Anupriya Narain,

E-mail: anupriyanarani@gmail.com

Copyright: ( $\odot$ the author(s), publisher and licensee Medip Academy. This is an open-access article distributed under the terms of the Creative Commons Attribution Non-Commercial License, which permits unrestricted non-commercial use, distribution, and reproduction in any medium, provided the original work is properly cited.

\begin{abstract}
Background: Several studies in the past two decades have proved beyond doubt that there is a high prevalence of hypovitaminosis D worldwide including India which has almost taken the shape of a pandemic. The study aims to determine the prevalence of hypovitaminosis D in the pregnant population of Delhi and its correlation with gestational diabetes mellitus.

Methods: This prospective cross sectional observational study was conducted at the Department of Obstetrics and Gynaecology, Postgraduate Institute of Medical Education and Research (PGIMER), Dr R.M.L Hospital, New Delhi over a period of 1 year and 4 months. Four hundred term patients were enrolled randomly from amongst the patients admitted in labor room or antenatal ward at PGIMER, Dr. Ram Manohar Lohia Hospital who fulfilled the inclusion and exclusion criteria. $3-4 \mathrm{ml}$ of fasting blood samples were collected of all the enrolled women and were analysed for total serum calcium levels and serum vitamin D levels. History of presence of gestational diabetes mellitus was noted along with any treatment history. The $25(\mathrm{OH}) \mathrm{D}$ levels for each subject was recorded and correlation of vitamin D levels with gestational diabetes mellitus was analysed. Statistical analysis was done using ANOVA/ Kruska Wallis test and Chi-Square test/ Fisher's exact test. A p value of $<0.05$ was considered statistically significant.

Results: The overall prevalence of vitamin D deficiency in the present study was $86.25 \%$. The overall mean serum vitamin D level was $14.06 \pm 9.43 \mathrm{ng} / \mathrm{ml}$. Thirty five out of 37 GDM patients had hypovitaminosis D i.e. $94.59 \%$. The prevalence of hypovitaminosis D among non-GDM population was $85.40 \%$. The association between GDM and Vitamin D deficiency was statistically non- significant in the present study with $\mathrm{p}$ value $=0.186$.

Conclusions: There is a very high prevalence of hypovitaminosis D in pregnant females attending present institute i.e. $86.25 \%$. Although $94.59 \%$ of Gestational Diabetes Mellitus patients had vitamin D deficiency, there is no statistically significant association between Gestational diabetes mellitus and serum vitamin D levels.
\end{abstract}

Keywords: Gestational diabetes mellitus, Hypovitaminosis D, Vitamin D deficiency

\section{INTRODUCTION}

Vitamin $\mathrm{D}$ is a fat-soluble vitamin having functions related to calcium metabolism and bone health. Vitamin $\mathrm{D}$ can be synthesized in the skin through exposure to sunlight, which remains the major source. Vitamin D deficiency is unexpected in a tropical country like India where there is abundant overhead sun for most or all of the year. The burden of vitamin D deficiency was found to be alarmingly high in pregnant women with serum levels $<15 \mathrm{ng} / \mathrm{ml}$ recorded in $66.7 \%$ population in a study done in Lucknow. ${ }^{1}$ However extrapolation of one data to any other population is elusive as the vitamin D status in the body remains influenced by skin colour, latitude, 
season, diet as well as life style and cultural practices which determine the amount of sun exposure.

There is little information on the ideal vitamin $\mathrm{D}$ regimen to prevent and treat vitamin D insufficiency. The existing guidelines suggest the RDA of vitamin D as $600 \mathrm{IU} /$ day during pregnancy. Newer studies have found doses of even up to $4000 \mathrm{IU} /$ day to be safe and more efficacious. ${ }^{2}$ Currently there are no separate cut off levels of vitamin D insufficiency and deficiency in pregnancy. The existing cut off levels might be erroneous for pregnant and lactating females. This warrants the need for further studies for setting appropriate threshold values for initiating vitamin $\mathrm{D}$ therapy during pregnancy.

It has been estimated that the total prevalence of GDM is almost $15-20 \% .^{3}$ In vitro and animal studies have also suggested that vitamin D has important roles in glucose and insulin metabolism. ${ }^{4-6}$ There are evidences which suggest that vitamin $\mathrm{D}$ improves the insulin sensitivity by enhancing insulin responsiveness to glucose transport. ${ }^{6}$

Several Indian studies have shown high incidence of vitamin D deficiency in India despite plenty of sunshine in most parts of India. Current study attempts to find the status of vitamin D deficiency in pregnant women attending present hospital and to determine whether this deficiency is also associated with higher incidence of gestational diabetes mellitus.

\section{METHODS}

This prospective cross sectional observational study was conducted at the Department of Obstetrics and Gynaecology, Postgraduate Institute of Medical Education and Research (PGIMER), Dr R.M.L Hospital, New Delhi over a period of 1 year and 4 months from November 2015 to March 2017.

This study was approved by the institutional ethics and research review board. Four hundred patients were enrolled randomly from amongst the patients admitted in labor room or antenatal ward at PGIMER, Dr. Ram Manohar Lohia Hospital who fulfil the inclusion and exclusion criteria.

\section{Inclusion criteria}

All term (37 weeks-42 weeks) singleton pregnancies booked in the Dr. RML Hospital antenatal clinic within the study period.

\section{Exclusion criteria}

- Patients with history of recent intake (i.e. within one year) of therapeutic doses of vitamin D.

- With known hypertension, renal disorders and Diabetes mellitus.

- Untreated and uncontrolled thyroid disorder.
- Detailed history followed by general physical and systemic examination was done.

Gestational diabetes mellitus was defined as carbohydrate intolerance of variable severity with onset or first recognition during pregnancy; diagnosed by 1 or more abnormal values in $75 \mathrm{gm}$ glucose tolerance test. History of presence of gestational diabetes mellitus was noted along with any treatment history.

$3-4 \mathrm{ml}$ of fasting blood samples were collected of all the enrolled women by venipuncture in a plain vacutainer and kept at room temperature for 30-60 minutes. It was then transported to laboratory and serum was separated by centrifugation at $3000 \mathrm{rpm}$ for 10 minutes and transferred to Eppendorf tubes. Serum was analysed for total serum calcium levels by Arsenazo colorimetric method on fully automated clinical chemistry analyser. Serum were stored -20degree centigrade for batch analysis of serum $25(\mathrm{OH})$ vitamin D. Samples were then analysed for serum vitamin $D$ levels by chemiluminescence immunoassay method on ECiQ vitros from Johnson's and Johnson's.

Serum calcium levels between 8.5 and $10.5 \mathrm{mg} / \mathrm{dl}$ was considered normal. The $25(\mathrm{OH}) \mathrm{D}$ levels for each subject was recorded. Correlation of vitamin D levels with gestational diabetes mellitus was analysed.

As per the recommendation of Institute of Medicine classification of $25(\mathrm{OH})$ vitamin D levels were taken as follows:

- $\quad<20 \mathrm{ng} / \mathrm{ml}$ : deficiency

- $20-<30 \mathrm{ng} / \mathrm{ml}$ : insufficiency

- $\quad 30-100 \mathrm{ng} / \mathrm{ml}$ : sufficiency

- $>100 \mathrm{ng} / \mathrm{ml}$ : potential toxicity.

\section{RESULTS}

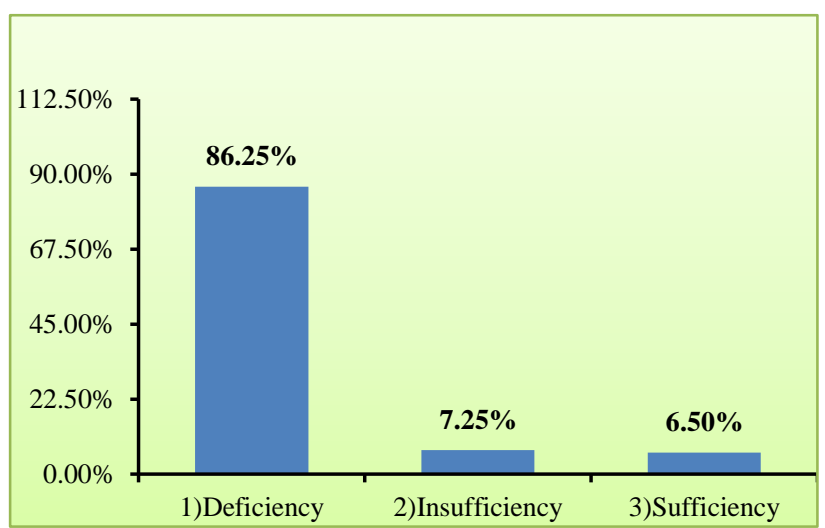

Figure 1: Vitamin D levels distribution in the study population.

The overall prevalence of vitamin D deficiency in the present study was $86.25 \%$. 
Another $7.25 \%$ were vitamin D insufficient and only $6.5 \%$ had sufficient vitamin D levels (Figure 1).

No patient had toxic levels of vitamin D. The overall mean serum vitamin D level was $14.06 \pm 9.43 \mathrm{ng} / \mathrm{ml}$.

The mean serum vitamin $\mathrm{D}$ levels in the control (uncomplicated group) and GDM was $14.4 \mathrm{ng} / \mathrm{ml}$ and $11.65 \mathrm{ng} / \mathrm{ml}$ respectively (Figure 2 ).

Thus, it was found that the mean vitamin D levels in the GDM group was lower than the uncomplicated group.

However, this association was not statistically significant (p-value $=0.339)$.

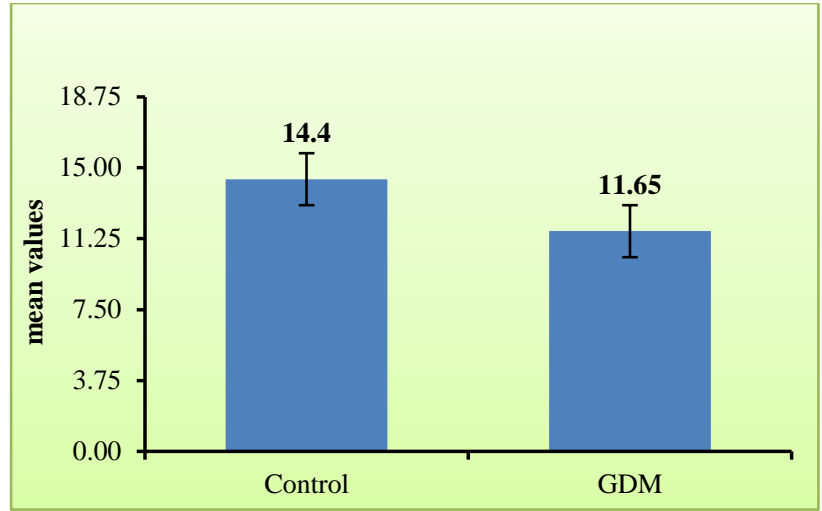

Figure 2: Bar graph for mean serum vitamin D levels in control and GDM group.

Table 1: Correlation between serum calcium and serum vitamin D level.

\begin{tabular}{|c|c|c|c|c|c|}
\hline \multirow{2}{*}{ Serum calcium (mg/dl) } & \multicolumn{3}{|c|}{ S. Vit D levels distribution } & \multirow{2}{*}{ Total } & \multirow{2}{*}{ P-value } \\
\hline & Deficiency & Insufficiency & Sufficiency & & \\
\hline$<8.5$ & $48(92.31 \%)$ & $3(5.77 \%)$ & $1(1.92 \%)$ & $52(100.00 \%)$ & \multirow{5}{*}{0.390} \\
\hline $8.5-9.5$ & $180(85.71 \%)$ & $18(8.57 \%)$ & $12(5.71 \%)$ & $210(100.00 \%)$ & \\
\hline $9.5-10.5$ & $105(84.68 \%)$ & $8(6.45 \%)$ & $11(8.87 \%)$ & $124(100.00 \%)$ & \\
\hline$>10.5$ & $12(85.71 \%)$ & $0(0.00 \%)$ & $2(14.29 \%)$ & $14(100.00 \%)$ & \\
\hline Total & $345(86.25 \%)$ & $29(7.25 \%)$ & $26(6.50 \%)$ & $400(100.00 \%)$ & \\
\hline
\end{tabular}

The mean serum calcium level in the present study was within normal limits i.e. $9.27 \pm 0.77 \mathrm{mg} / \mathrm{dl}$. Out of 345 vitamin $\mathrm{D}$ deficient patients, only 48 had calcium deficiency i.e. $13.9 \%$ as compared $3.8 \%$ of the vitamin D sufficient group. However, this was not significant with a $p$ value $=0.227$. Out of 345,297 i.e. $86.08 \%$ of vitamin D deficient patients had normal serum calcium levels. The relation between serum calcium and serum vitamin $\mathrm{D}$ levels was not statistically significant ( $\mathrm{p}$ value $=0.390$ ) (Table 1). The mean calcium levels in the sufficient group was slightly higher than the deficient and insufficient group (Figure 3).

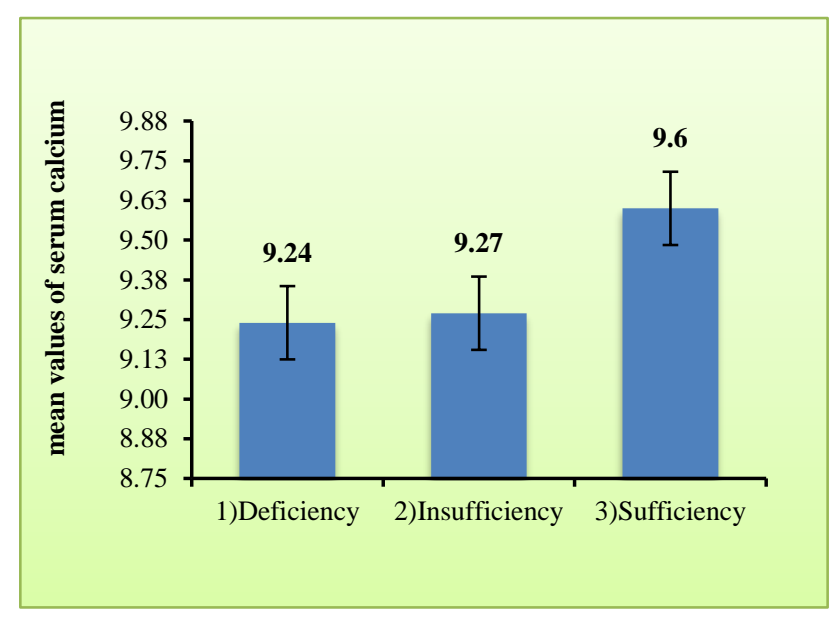

Figure 3: Correlation of mean serum calcium with vitamin D levels.

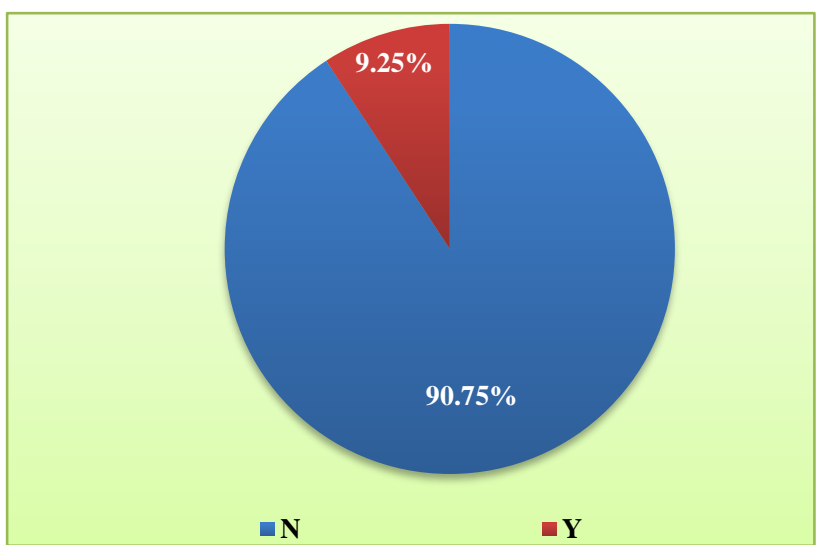

Figure 4: Incidence of GDM among study population.

Out of 400 participants, 37 had GDM (9.25\%) (Figure 4). The prevalence of hypovitaminosis D amongst the GDM patients was $94.59 \%$.

The prevalence of hypovitaminosis D among non-GDM population was $85.40 \%$.

In the present study the incidence of GDM was $10.14 \%$ and $7.69 \%$ in the patients with and without hypovitaminosis D respectively (Figure 5).

However, the association between GDM and Vitamin D deficiency was statistically non-significant in the present study with $\mathrm{p}$ value $=0.186$. 


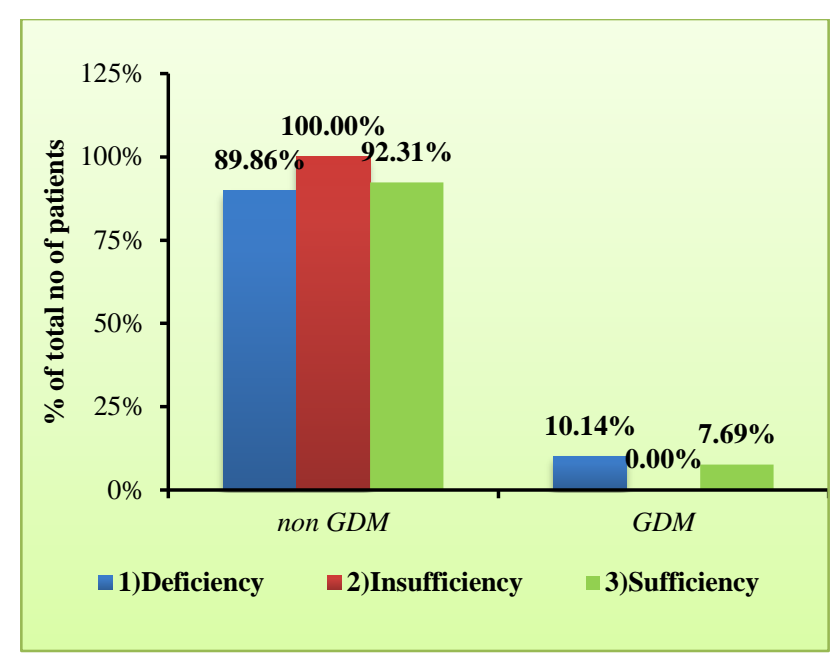
Figure 5: Correlation between GDM and
vitamin D deficiency.

\section{DISCUSSION}

The overall prevalence of vitamin D deficiency in the present study was $86.25 \%$. This was despite the fact that $100 \%$ patients had taken 400 IU vitamin D supplements per day during second and third trimester. This was similar to results obtained by Kazemi et al who also reported $86 \%$ incidence of vitamin D deficiency and by Sachan et al. ${ }^{1,7}$

Another $7.25 \%$ were vitamin D insufficient and only $6.5 \%$ had sufficient vitamin D levels. The mean serum vitamin D level was $14.06 \pm 9.43$.

The mean serum vitamin D levels in the control (uncomplicated group) and GDM was $14.4 \mathrm{ng} / \mathrm{ml}$ and $11.65 \mathrm{ng} / \mathrm{ml} \mathrm{respectively.} \mathrm{Thus,} \mathrm{it} \mathrm{was} \mathrm{found} \mathrm{that} \mathrm{the}$ mean vitamin D levels in the GDM group was lower than the uncomplicated group. However, this association was not statistically significant ( $\mathrm{p}$ value $=0.339$ ).

It can be hypothesised that the high prevalence of hypovitaminosis $\mathrm{D}$ in the pregnant females may be secondary to the hemodilution or other physiological changes of pregnancy. Thus, similar to other biochemical parameters, separate cut off levels for vitamin D levels might be needed to diagnose hypovitaminosis $\mathrm{D}$ in pregnancy. Further research needs to be undertaken to strengthen or reject this hypothesis.

The mean serum calcium level in the present study was $9.27 \pm 0.77 \mathrm{mg} / \mathrm{dl}$ which lies within the normal range. Out of 400,52 patients $(13 \%)$ had serum calcium below 8.5 $\mathrm{mg} / \mathrm{dl}$. The incidence of low serum calcium in vitamin D sufficient patients was $3.8 \%$ as compared to $13.9 \%$ in vitamin D deficient patients.

However, the relation between serum calcium and serum vitamin D levels was not statistically significant ( $p$ value $=0.390)$.
Out of 400 participants, 37 had GDM (9.25\%). Except 2 all the GDM patients had hypovitaminosis D i.e. $94.59 \%$. But they constituted only $10.14 \%$ of vitamin D deficient group. This can be attributed to the overall high prevalence of vitamin $\mathrm{D}$ deficiency in the general population in this study. The prevalence of hypovitaminosis D among non-GDM population was $85.40 \%$. Although the association between vitamin D levels and GDM was not found to be statistically significant, it does point towards increased prevalence of vitamin D deficiency amongst GDM group.

Similar results were obtained by Farrant et al. ${ }^{8} \mathrm{He}$ reported $7 \%$ incidence of GDM in women with or without hypovitaminosis D and suggested that although vitamin D insufficiency is common in Indian mothers it is not associated with gestational diabetes. In the present study the incidence was $10.14 \%$ and $7.69 \%$ in the patients with and without hypovitaminosis D respectively. Likewise, Baker et al found no association between 25(OH)D level and the odds of GDM. ${ }^{9}$ In addition, Makgoba and colleagues in their case control study reported no association between first trimester blood samples and subsequent development of GDM. ${ }^{10}$

In contrast Kumari et al reported a significantly lower mean vitamin D level in GDM women $12.62 \pm 6.69 \mathrm{ng} / \mathrm{ml}$ as compared to controls $24.25 \pm 14.44 \mathrm{ng} / \mathrm{ml}$ (median= $18.2 \mathrm{ng} / \mathrm{ml})(\mathrm{P}<0.05) .{ }^{11}$ Similarly Mojibian et al found that maternal $25(\mathrm{OH}) \mathrm{D}$ concentration at 24-28 weeks of gestation were significantly lower in women with GDM. ${ }^{12}$ In addition to this, Aghajafari et al in their metaanalysis of 10 studies concluded that $25(\mathrm{OH}) \mathrm{D}$ levels $<75$ $\mathrm{nmol} / \mathrm{L}$ were associated with increased odds of GDM (OR 1.49 (95\% confidence interval 1.18 to 1.88$).{ }^{13}$ Parlea et al after adjusting for gestational age and maternal weight, concluded that low serum 25 hydroxy vitamin D was associated with a twofold greater likelihood of gestational diabetes which was independent of race, age, season and maternal weight. ${ }^{14}$ Zhang $\mathrm{C}$ et al in a nested case-control study in Washington in 2008 concluded that maternal plasma $25(\mathrm{OH}) \mathrm{D}$ concentrations were $20 \%$ lower among women who subsequently developed gestational diabetes mellitus as compared to those who were not diagnosed with gestational diabetes mellitus. ${ }^{15}$

To further establish the association between glucose intolerance and hypovitaminosis $\mathrm{D}$, interventional studies have been undertaken in the past few years. Jayaraman et al reported that frequency of GDM was similar irrespective of vitamin D status $67 \%$ versus $42 \%$ (p value $=0.09) .{ }^{16}$ However, serum 25-OH Vitamin D levels were significantly lower in GDM $24.7( \pm 17.6) \mathrm{ng} / \mathrm{ml}$ versus normal glucose tolerance group $(45.8 \pm 28)$ group ( $\mathrm{p}$ value $=0.0004$ ). The investigators went on to conclude that replacement of vitamin $D$ in the form of supplementation does not reverse the glucose intolerance. In a randomised controlled trial conducted in 2015, Mojibian M et al compared the effects of 50,000 IU of vitamin D every two weeks with that of $400 \mathrm{IU}$ of 
vitamin D daily. ${ }^{12}$ The researchers concluded that 50,000 IU vitamin D every 2 weeks decreases the incidence of GDM.

\section{CONCLUSION}

There is a very high prevalence of hypovitaminosis D in pregnant females attending present institute i.e. $86.25 \%$. Although $94.59 \%$ of Gestational Diabetes Mellitus patients had vitamin D deficiency, there is no statistically significant association between Gestational diabetes mellitus and serum vitamin D levels.

Funding: No funding sources

Conflict of interest: None declared

Ethical approval: The study was approved by the Institutional Ethics Committee

\section{REFERENCES}

1. Sachan A, Gupta R, Das V, Agarwal A, Awasthi P $\mathrm{K}$, Bhatia V. High prevalence of vitamin D deficiency among pregnant women and their newborns in northern India. Am $\mathbf{J}$ Clin Nutr. 2005;81:1060-4.

2. Hollis BW, Wagner CL. Vitamin D requirements during lactation: high-dose maternal supplementation as therapy to prevent hypovitaminosis D for both the mother and the nursing infant. Am J Clin Nutr.2004;80:1752S-8S.

3. American Diabetes Association. Standards of medical care in diabetes. Dia Care.2014;37(1):S14S80.

4. Holick MF. Vitamin D: importance in the prevention of cancers, type 1 diabetes, heart disease, and osteoporosis. Am J Clin Nutr. 2004;79:362-371.

5. Pittas AG, Lau J, Hu FB, Dawson-Hughes B. The role of vitamin $\mathrm{D}$ and calcium in type 2 diabetes. A systematic review and meta-analysis. J Clin Endocrinol Metab. 2007;92:2017-29.

6. Maestro B, Molero S, Bajo S, Davila N, Calle C. Transcriptional activation of the human insulin receptor gene by 1,25-dihydroxyvitamin $\mathrm{D}(3)$. Cell Biochem Funct. 2002;20:227-32.

7. Kazemi A, Sharifi F, Jafari N, Mousavinasab N. High prevalence of vitamin $\mathrm{D}$ deficiency among pregnant women and their newborns in an Iranian population. J Women's Health (Larchmt). 2009 June;18(6):835-9.

8. Farrant HJ, Krishnaveni GV, Hill JC. Vitamin D insufficiency is common in Indian mothers but is not associated with gestational diabetes or variation in newborn size. Eur J Clin Nutr. 2009;63(5):646-52.

9. Baker AM, Haeri S, Camargo CA, Jr, Stuebe AM, Boggess KA. First-trimester maternal vitamin D status and risk for gestational diabetes (GDM) a nested case-control study. Diabetes Metab Res Rev. 2012;28:164-8.

10. Makgoba M, Nelson SM, Savvidou M, Messow CM, Nicolaides K, Sattar N. First-trimester circulating 25hydroxyvitamin D levels and development of gestational diabetes mellitus. Diabetes Care. 2011;34:1091-3.

11. Kumari A, Mitra S, Tiwari HC, Srivastav R, Hypovitaminosis D in pregnancy and its correlation with preeclampsia and gestational diabetes mellitus. Int J Reprod Contracept Obstet Gynaecol. 2017;6:890-6.

12. Mojibian M, Soheilykhah S, Fallah Zadah MA, Moghadam MJ. The effects of vitamin D supplementation on maternal and neonatal outcome: a randomised clinical trial. Iran J Reprod Med. 2015 Nov; 13(11):687-96.

13. Aghajafari F, Nagulesapillai T, Ronksley $P$, Tough S, O'Beirne M, Rabi D. Association between maternal serum 25-hydroxyvitamin $\mathrm{D}$ level and pregnancy and neonatal outcomes: systematic review and meta-analysis of observational studies. Bri Med J. 2013;346:f1169.

14. Parlea L, Bromberg IL, Feig DS, Vieth R, Merman E, Lipscombe LL. Association between serum 25hydroxyvitamin D in early pregnancy and risk of gestational diabetes mellitus. Diabet Med. 2012;29:e25-32.

15. Zhang C, Qiu C, Hu FB, David RM, Van Dam RM, Bralley A, et al. Maternal plasma 25-hydroxyvitamin $\mathrm{D}$ concentrations and the risk for gestational diabetes mellitus. PloS one. 2008 Nov 18;3(11):e3753.

Cite this article as: Narain A, Goel A, Goyal P. Estimation of maternal serum vitamin D levels and its correlation with gestational diabetes mellitus. Int J Reprod Contracept Obstet Gynecol 2018;7:3348-52. 